\title{
Francesco Cocco
}

\section{The Torah as a Place of Refuge}

\section{Biblical Criminal Law and the Book of Numbers}

[Die Tora als Zufluchtsort. Biblisches Strafrecht und das Buch Numeri.]

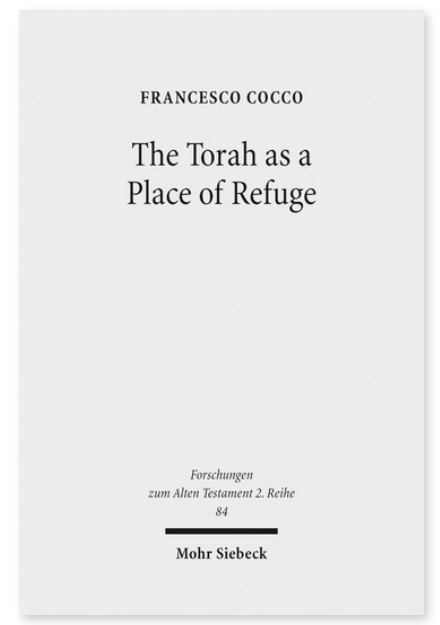

2016. XII, 185 Seiten. FAT II 84

ISBN 978-3-16-154352-4

DOI 10.1628/978-3-16-154352-4

eBook PDF $69,00 €$

ISBN 978-3-16-154138-4

fadengeheftete Broschur 69,00€
Veröffentlicht auf Englisch.

Das Gesetz zu den »Asylstädten« in Num 35.9-34 wird beinahe überall als schlichte Wiederholung der Gesetztestexte gesehen die prinzipiell schon in den Gesetzgebungen anderer Bibeltexte enthalten sind. Francesco Cocco zeigt, dass es sich hier statt um Wiederholung um eine Neuformulierung handelt, deren Auswirkungen für das Verständnis des Strafrechts in der Bibel äußerst interessant sind. In diesem speziellen Teil weist es eine überraschende Modernität auf, die mit Garantien von Bürgerrechten in aktuellen Rechtssystemen der meisten demokratischen Staaten vergleichbar ist.

Der Autor beginnt seine Analyse demnach bei diesem neuartigen Beitrag, den die Gesetzgebung in Num 35.9-34 zur strafrechtlichen Gesetzgebung der Bibel leistet und entwickelt sie von dort aus weiter.

Francesco Cocco Born 1975; studied at the Theological Institute of Assisi (Italy) and at the Pontifical Biblical Institute (Rome); 2006 doctorate in Sacred Scriptures from the Pontifical Biblical Institute (Rome); currently Professor of Old Testament Exegesis (Pentateuch) at the Pontifical Urbaniana University (Rome, Italy).

\section{Jetzt bestellen:}

https://mohrsiebeck.com/buch/the-torah-as-a-place-of-refuge-9783161543524?no_cache=1 order@mohrsiebeck.com

Telefon: $+49(0) 7071-923-17$

Telefax: +49 (0)7071-51104 